\title{
Analysis of Impact of Culture Shock on Individual Psychology
}

\author{
Junzi Xia \\ International Communications Department, University of Nottingham Ningbo \\ 199 Taikang East Road, Ningbo 315100, China \\ Tel: 86-379-6421-9460_E-mail: xia831223@163.com
}

\begin{abstract}
In recent years, international communication has become a common phenomenon because of the trend of globalization. This makes culture shock start to be experienced by more people and causes growing concern. This project takes the negative effects of culture shock into account and pays attention to how to minimize psychological discomfort when entering new cultural patterns. First of all, the main reason and the negative impact of culture shock are given. Next, it describes a number of solutions and evaluates the effectiveness of them. Finally, this paper justifies the preferred choice of solution, and then noticeable points are emphasized. Considering that character and disposition may be various among different people, it is found that in order to attain satisfactory results, choosing appropriate methods and reducing psychological stress to the controllable level are very important. This may be helpful for people who are experiencing culture shock to keep a healthy psychology.
\end{abstract}

Keywords: Psychology, Culture shock, International communications

\section{Introduction}

In recent decades, the peoples of the world have been brought closer and closer by fast technological development in transportation and communication. Today, the rapid globalization of world economies is making the need for understanding cultural diversity become more and more inevitable. Under this circumstance, cross-cultural communication is becoming a global issue. As a result, individual ability to adjust to a new culture is being paid increased attention (Ferraro, 2006). During the process of cultural adjustment, difficulties and problems in communication are usually caused by a change of emotion from cheerful and relaxed to sad and depressed. This is a common phenomenon for those people who face an unfamiliar culture (Hess, 1994). The term culture shock was introduced by an anthropologist Kalervo Oberg to describe this situation. According to Oberg, culture shock may be defined as the psychological disorientation experienced by people who suddenly enter radically different cultural environments to live and work (Eschbach et al, 2001). So as a kind of emotional responding to stress, culture shock has a close relationship to individual psychology.

The purpose of this project is to describe the impact of culture shock on individual psychology and give specific solutions. First it will introduce the main reason for culture shock. Then the negative impact of culture shock on individual psychology will be given. Next, it will give corresponding solutions from two stages: pre-departure and during the experience. The first stage will emphasize how to make preparations for culture shock before going abroad, and the second stage will put stress on how to overcome psychological stress when people experience culture shock. Finally, it will evaluate the effectiveness of each solution. Through this project, the nature of culture shock will unfold, especially from the psychological angle. Since it is possible that psychological adaptation can influence success or failure of overseas living, as Ferraro (2006) claims, analysing culture shock from the psychological aspect may help people understand culture shock fully and increase the probability of successful overseas living.

\section{Culture Shock}

\subsection{Reason for culture shock}

First of all, in order to decrease the negative impact of culture shock on individual psychology, it is necessary for people to find out its origins. It seems that culture is a vague concept, which includes extensive content such as sight, smell, sound, value, tradition, custom, behaviour and the way of thinking. All these elements may be different from one country to another. Therefore when people are away from home and enter a new environment, they have to come into contact with many new values, new practices and ways of living. This is especially true for those people who face a new cultural pattern which is different from their own ones. Take the differences between high-context and low-context cultures as an example. In the latter, such as the United States and Britain, more attention is paid to the content of talk, 
and people often feel a strong need to explain their opinions in detail. Verbal language plays the most important role in communication, while nonverbal language such as body language and facial expression are secondary. However, high-context cultures are opposite. In most areas of Latin America, Asia, the Middle East and Africa, people usually focus less on what is being said, and nonverbal cues are significant methods of communication (Mitchell, 2000).

It appears that all people may experience culture shock when they encounter other circumstances which are dissimilar to their former cultural contexts. For expatriates, this change or unfamiliarity makes them fail to understand the ideology and behaviour of local people so that they do not know why those people behave as they do and how they themselves should behave. When these people lose all familiar signs and symbols of social intercourse, they have to try to adapt themselves to different lifestyles, living conditions and business practices in a new cultural setting. However, this is a long term and difficult process. In this condition, feelings of alienation accumulate sharply because of poor adaptation. Consequentially, culture shock occurs, followed by a series of psychological confusion and emotional discomfort (Hess, 1994).

\subsection{Negative impact of culture shock}

Change may cause stress. When people encounter a new culture and experience culture shock, change and unfamiliarity influences their own psychological adjustment and participation in a cultural environment. This psychological confusion and emotional discomfort usually causes a tremendous amount of psychological stress (Eschbach et al, 2001). The negative impact of culture shock on individual psychology often includes a large and diverse set of symptoms. Although not everyone will experience all the symptoms, almost all people will experience some parts. The major symptoms may be described as depression, anxiety and feelings of helplessness (Mio, 1999). If depression, anxiety and feelings of helplessness accumulate, the degree and extent of psychological disorientation may be deeper and deeper so that people may have difficulties in paying attention to the learning of new cultures. Moreover, psychological disorientation may influence people's abilities to solve problems and to make decisions. This decreases the motivation for adapting to the new conditions. Most important is that when people fail to defeat the symptoms of culture shock, they are likely to become hostile to host nationals, which may lead to a handicap of interpersonal relationship (Ferraro, 2006). Therefore it appears that dealing with psychological stress caused by culture shock such as depression, anxiety and feelings of helplessness is significant for those people who come into contact with a new culture.

\section{Reduction of Psychological Stress: Pre-Departure}

In order to decrease psychological stress, people have to make many preparations for culture shock before they go abroad. This period is usually called pre-departure. It is essential and indispensable. If a person is able to make good use of this stage, the impact of culture shock on his psychology will decrease obviously (Cushner, 1994). There are two main methods to be considered in this period: understanding the four stages of culture shock and becoming familiar with the new culture.

\subsection{Understanding the four stages of culture shock}

First of all, the stages of culture shock should be understood, which can help people predict the difficulties they may experience in a new cultural environment. It has four phases, and each stage can appear only at certain times and show different features. The term "honeymoon" can be used to describe the initial stage. In this stage, people who enter other cultures may be pleased by all of the new things encountered. Then, the second stage emerges after a few weeks. It may start with a series of negative experiences and escalating problems. Culture shock occurs because of inappropriate behaviour in the new cultural environment, which results in a large amount of stress and increasing depression, anxiety, tension and confusion. After that, the adjustment stage appears followed by increased ability to learn how to adjust effectively to the new cultural pattern. A variety of adaptation will be achieved during this phase, so negative effects of culture shock begin to become less and less. The fourth stage is the mastery stage which often comes after one and a half years. In this phase, people are able to solve problems and manage new cultures successfully, and symptoms of culture shock disappear largely (Janssens, 1995).

An understanding of the four phases may provide large help for all people who are prepared against psychological stress caused by culture shock. The reason may be analysed from two aspects. Firstly, it is probable that vague and indistinct events may cause more stress. Therefore people should understand what the problems are, and then they can solve them. It seems that having a comprehensive understanding of events may decrease stress and negative emotions. Secondly, unpredictable or uncontrollable events are more likely to cause stress. It suggests that prediction plays an important part in the reduction of stress and psychological disorientation (Lafreniere \& Cramer, 2005). For most people, culture shock is a strange event, which is not only undefined, but also unpredictable, so if these people experience culture shock, their psychological health will be influenced to a great extent. However, if they know the stages of culture shock, they can predict what may happen in the each stage. This may make them face difficulties and troubles leisurely and calmly, and the degree of depression, anxiety and feelings of helplessness may also be alleviated (Jacobs, 2003). 


\subsection{Becoming familiar with new culture}

The four phases of culture shock suggest that adaptation to a new culture is a chronic process, so how to shorten the time of adjust to the new conditions is very helpful for those people who face a new cultural pattern. It appears that becoming familiar with the new environment before departing may be the best method to attain this goal. The main reason is that it can provide an intellectual tool for better understanding why other individuals or groups of people are similar or different. Through the familiarity with the new culture, people can imagine many possible obstacles they will encounter. This makes new surroundings become more acceptable and easier to adjust to (Ferraro, 2006). Therefore, being familiar with a new culture may be considered as the second solution to reduce the negative impact of culture shock on individual psychology.

The more thorough the understanding of a new culture, the smaller the negative impact there will be, because knowledge about the host culture enhances individual capacity to adjust to the new circumstances (Coodman, 1994). For example, in different cultures, much nonverbal behaviour may be different, such as physical space between two talkers. Compared with Americans, Saudi Arabians are accustomed to standing closer in communication. Twenty inches is a normal distance for Americans, but for Saudi Arabians, it means unfriendliness so that they may move closer to make conversation more comfortable. This can be viewed as impolite and uncouth by Americans. Consequently, when a Saudi Arabian enters America, psychological discomfort appears, because they are ill prepared to cope with culture shock and lack relevant knowledge (Ferraro, 2006). According to the example, knowledge and understanding of the new environments can help people study how to behave better. This may lessen psychological disorientation and make people accept new culture as soon as possible. Therefore, the time of experiencing depression and anxiety will be shortened. This method may take much time, and it is impossible to understand all aspects of the new cultures, but it is easy to put into practice and effective because of rich data and information. They can be got from a number of scholarly sources such as books, journal articles and other sources like newspapers and the internet (Ferraro, 2006).

\section{Reduction of Psychological Stress: During the Experience}

Although pre-departure is a significant period for all people who want to minimize psychological stress caused by culture shock, living and working abroad is a more important period which is called during the experience. It seems that full preparation can improve people's abilities to adjust to new surroundings and make them become more self-confident. However, culture shock will never be totally avoided, because a good preparation only decreases its influence. Therefore, how to reduce psychological stress in the period of during the experience should be considered carefully. In this stage, people have to transform knowledge into practice when they experience stress-related symptoms (Cushner, 1994). When people encounter culture shock, there are three approaches to reduce psychological stress: self-confidence and optimism, accepting new culture and seeking social support.

\subsection{Self-confidence and optimism}

In the field of social psychology, there is a term self-efficacy which means the conviction or belief of people that they can overcome the obstacles encountered. People with high self-efficacy usually believe that they have abilities to perform tasks well. They work harder and experience less anxiety when getting into trouble, because they have full confidence that they will succeed. Nevertheless, people with low self-efficacy often believe that they cannot perform works well, so they usually tend to give up easily and experience more anxiety when facing troubles. Lack of confidence is the most important reason for their failure (Aronson et al, 2005). Therefore, self-confidence plays a key role in decreasing anxiety and overcoming obstacles.

Likewise, optimism is also very necessary when people experience culture shock, because explaining negative events optimistically can decrease depression and anxiety. This has been proved through scientific research made by Tim Wilson and Patricia Linville in the 1980s (Aronson et al, 2005). First of all, they chose many first-year students who experienced academic difficulties because of the difficulty of adjusting to a new academic environment. When these students did not realize that such adjustment problems are very common and pessimistically assumed that their problems resulted from personal abilities, they were likely to be depressed and anxious. However, when these students optimistically assumed that poor performance was a normal phenomenon and may improve afterwards, they made progress. Therefore, a mood of pessimism may increase psychological stress, while an optimistic attitude may reduce depression and anxiety in a new academic situation. Similarly, when people enter a new cultural environment and experience culture shock, optimism often make them react better to stress, so it exerts positive effects on the reduction of psychological burden.

Although different people use various ways to try to minimize the impact of culture shock on their psychology, it seems that keeping self-confident and optimistic may be the most effective. However, it is difficult for a number of people in the process of cultural adaptation, since people's personalities are diverse. Many people are optimistic and self-confident naturally, but others may tend to see negative events pessimistically. This is hard to change (Aronson et al, 2005). Moreover, unrealistic and excessive optimism or self-confidence would result in many grave consequences. For 
instance, excessively optimistic people may enter a new environment without any preparation. This will make them experience more serious culture shock (Ferraro, 2006). Thus, a moderate self-confidence and an optimistic mood are necessary for people to deal with culture shock. Firstly, the change should be thought of as a normal part of the adjustment process rather than threat, and then people should view it as a challenge and try their best to defeat it (Davis $\&$ Palladino, 2000).

\subsection{Acceptance of new culture}

The second method is acceptance, which means accepting other cultures' values and behaviours as not good or bad but simply different. Once people are able to accept them, they will be more comfortable and able to minimize psychological stress. Nevertheless, it is not an easy method. People need to understand with great willingness and pleasure not only what people do and believe, but also why they do it. Therefore, interest, curiosity and willingness are essential, and reluctant acceptance will cause more psychological discomfort (Phillips, 2003). However, not all parts of a different culture can be accepted. This is a normal phenomenon. Under this condition, tolerance and keeping an open mind toward local culture may be easier than willing acceptance. In addition, making an attempt to respect local customs and traditions may be also a relatively easy way, which could be a prerequisite for the acceptance of new culture. For example, people usually smile when they want to express happiness and friendly attitude in most countries. However, in many Asian countries, smiling is a sign of weakness, and people are likely to talk with each other without smiling. Therefore, people who enter these Asian countries from other cultural backgrounds may feel that local people are unfriendly. It may be difficult for people to accept this difference with pleasure, but a tolerant attitude and an open mind may make them communicate better with the host nationals (Ferraro, 2006).

\subsection{Social support}

Finally, seeking social support is also regarded as an effective way during the anti-stress process, which means people receive consolation, caring, encouragement, advice, approval and help from others around them. It seems that people who have friends to lean on deal with stress better. When social support decreases, common psychological problems such as depression, anxiety and feelings of helplessness increase. Research in different cultures provides evidence for the importance of social support. People who live in cultures that stress interdependence suffer less from psychological stress than people who live in cultures that emphasize independence. Therefore, social support plays a role in reducing possible negative side effects of major life events and daily hassles (Lafreniere \& Cramer, 2005). For instance, when people encounter many difficulties such as culture shock, their friend may help them analyze the reason and give them a number of suggestions about how to do better in future (Aronson et al, 2005).

People who are able to develop friendly relationships with local nationals will get more social support easily, whereas others who are not good at social intercourse may fail to do this. Therefore, they often seek social support through other ways. For most people, one desirable way is keeping in touch with members of family through email or satellite phone. These modern tools of communication create a better chance for people who are far away from home to communicate with their parents. This may reinforce people's senses of security. Moreover, depression, anxiety and feelings of helplessness may be reduced, because people usually feel that they can freely express fears and stress and comfortably receive encouragement and support from other family members (Scheyvens, 2003).

\section{Application and Problems}

\subsection{Choice of methods}

After giving a number of methods and evaluations for coping with the negative impact of culture shock on individual psychology, it appears that not every method is very effective for all people, so choosing suitable solutions is significant. Understanding the process of culture shock and being familiar with new cultural patterns may be two favourable methods. They are suitable and effective for all people who want to reduce psychological stress result from culture shock, because it is easy for people to collect relevant information through books and the internet. However, people who choose these methods have to take much time to accumulate new knowledge as much as possible and make full preparations. It is generally agreed that although people cannot avoid culture shock completely, preparation may add to their capacities to overcome stress when facing it (Cushner, 1994). Compared with them, self-confidence and optimism, accepting the new culture, and seeking social support are also feasible, but their effects are easily influenced by disposition and character. Nevertheless, for those people who are self-confident, optimistic, and good at making friends, these methods are long term solutions. If they adopt these ways, even though they are unfamiliar with the new culture, it is possible for them to control psychological stress successfully. Therefore, appropriate and suitable methods should be chosen according to individuality.

\subsection{Advantages of stress}

It is found that reduction of psychological stress is significant when entering new cultural environments. However, there is a key point should be taken into account carefully. It is that dealing with culture shock does not mean the thorough elimination of negative emotion. Firstly, it is impossible to eliminate stress completely. Secondly, a certain amount of 
anxiety and depression may provide motivation for people to learn the new culture and adjust to the cross-cultural environment (Ferraro, 2006). Therefore, facing stress with the right attitude and transforming negative emotion into positive motivation may help people keep psychological health and minimize culture shock successfully.

\section{Conclusions}

In the process of international communication, culture shock is becoming more and more common because of cultural diversity. From one culture to another, the differences among them cause people's feelings of unfamiliarity. This results in a large amount of psychological stress such as depression, anxiety and feelings of helplessness. This paper has given five solutions and evaluations about how to deal with these symptoms caused by culture shock. Before entering a new cultural environment, it is very important for all people to make full preparation. Understanding the process of culture shock and features of a new culture may be useful for all people, because knowledge can be acquired through a number of channels. Then, when experiencing culture shock, self-confidence and optimism, accepting new cultures and seeking social support may be three effective ways for most people to overcome psychological discomfort. In addition, a certain amount stress can stimulate passion for cultural learning which may speed up people's adaptation to new cultural circumstances. Therefore, reducing psychological stress to a controllable level should be more feasible than thorough elimination.

For those people who are on the point of entering new cultural environments to study or work, this project may provide advice and assistance for them to minimize the negative effects of culture shock and maintain healthy psychology. However, People who have lived abroad often find that the adjustment to returning home is more difficult than their adjustment to the foreign culture. This phenomenon is called reverse culture shock, which has been experienced by most people who return from abroad. Therefore, more scientific researches on reverse culture shock should be made in future years.

\section{References}

Aronson, E., Wilson, T. D., \& Akert, R, M. (2005). Social psychology (5th ed.). New Jersey: Pearson Education.

Coodman, N. R. (1994). Training for the global executive. In Brislin, R. W., \& Yoshida, T. (Eds), Improving intercultural interactions: Modules for cross-cultural training programs. London: Sage Publications.

Cushner, K. (1994). Cross-cultural training for adolescents and professionals who work with youth exchange programs. In Brislin, R. W., \& Yoshida, T. (Eds), Improving intercultural interactions: modules for cross-cultural training programs. London: Sage Publications.

Davis, S. F., \& Palladino, J. J. (2000). Psychology (3rd ed.), New Jersey: Prentice Hall.

Eschbach, D. M., Parker, G. E., \& Stoeberl, P. A. (2001). American repatriate employees' retrospective assessments of the effects of cross-cultural training on their adaptation to international assignments. International Journal of Human Resource Management, 12(2), 270-287.

Ferraro, G. P. (2006). The cultural dimension of international business (5th ed.). New Jersey: Pearson Education.

Hess, J. D. (1994). The whole world guide to culture learning, Yarmouth: Intercultural Press.

Jacobs, K. (2003). Culture shock. [Online] Available: http://www.hagshama.org.il/en/resources/view.asp?id=1445 (April $15,2008)$.

Janssens, M. (1995). Intercultural interaction: A burden on international managers. Journal of Organizational Behaviour, 16(2), 155-167.

Lafreniere, K. D., \& Cramer, K. M. (2005). Applying social psychology to health. In Schneider, F. W., Gruman, J. A., \& Coutts, L. M. (Eds), Applying social psychology: understanding and addressing social and practical problems, London: Sage Publications.

Mio, J. S. (1999). Key words in multicultural interventions: A dictionary. Westport: Greenwood Publishing Group.

Mitchell, C. (2000). Short course in international business culture. Novato: World Trade Press.

Phillips, J. (2003). In the know in Japan: the indispensable guide to working and living in Japan. Westminster: Random Information Group.

Scheyvens, R. (2003). Development fieldwork: a practical guide. London: Sage Publications. 